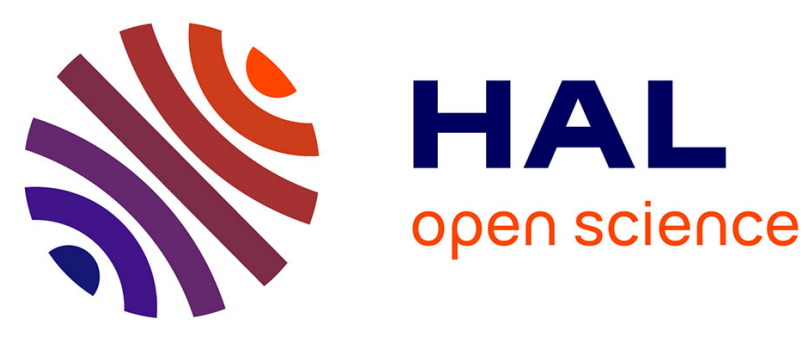

\title{
Comparison between the polar organic chemical integrative sampler and the solid-phase extraction for estimating herbicide time-weighted average concentrations during a microcosm experiment
}

Nicolas Mazzella, T. Debenest, François Delmas

\section{To cite this version:}

Nicolas Mazzella, T. Debenest, François Delmas. Comparison between the polar organic chemical integrative sampler and the solid-phase extraction for estimating herbicide time-weighted average concentrations during a microcosm experiment. Chemosphere, 2008, 73 (4), p. 545 - p. 550. 10.1016/j.chemosphere.2008.06.009 . hal-00454420

\author{
HAL Id: hal-00454420 \\ https://hal.science/hal-00454420
}

Submitted on 8 Feb 2010

HAL is a multi-disciplinary open access archive for the deposit and dissemination of scientific research documents, whether they are published or not. The documents may come from teaching and research institutions in France or abroad, or from public or private research centers.
L'archive ouverte pluridisciplinaire HAL, est destinée au dépôt et à la diffusion de documents scientifiques de niveau recherche, publiés ou non, émanant des établissements d'enseignement et de recherche français ou étrangers, des laboratoires publics ou privés. 
MAZZELLA, N., DEBENEST, T., DELMAS, F. - 2008. Comparison between the polar organic chemical

http://www.sciencedirect.com/science?_ob=ArticleListURL\&_method=list\&_ArticleListID=798074980\&_sort=d\&v

10 Comparison between the polar organic chemical integrative sampler

11 and the solid-phase extraction for estimating herbicide time-weighted average concentrations during a microcosm experiment 
35 Contacts:

$36 *$ Corresponding author.

38 E-mail: nicolas.mazzella@cemagref.fr; mazzelladibosco@yahoo.fr

39 Phone: +33557892718

40 Fax: +335 57890801

41 


\section{Abstract}

Polar organic chemical integrative samplers (POCIS) were exposed for 9 days in two 45 different microcosms that contained river waters spiked with deethylterbuthylazine, 46 terbuthylazine and isoproturon. The experiment was performed with natural light and strong 47 turbulence (flow velocities of about $15-50 \mathrm{~cm} \mathrm{~s}^{-1}$ ) for reproducing natural conditions. The 48 concentrations were kept relatively constant in the first microcosm $\left(2.6-3.6 \mu \mathrm{g} \mathrm{L}^{-1}\right)$ and were 49 variable in the second microcosm (peak concentrations ranged from 15-24 $\mu \mathrm{g} \mathrm{L}^{-1}$ during the 3 50 day pulse phase). The time-weighted average (TWA) concentrations were determined with both 51 POCIS and repetitive grab sampling followed by solid phase extraction. The results showed a 52 systematic and significant overestimation of the TWA concentrations with the POCIS most 53 probably due to the use of sampling rates derived under low flow scenario. The results showed 54 also that peak concentrations of pollutants are fully integrated by this passive sampler. Even if the

55 POCIS should not provide very accurate concentration estimates without the application of 56 adequate sampling rate values or the use of performance reference compounds, it can be a really 57 useful tool for detecting episodic or short-term pollution events (e.g. increased herbicide 58 concentrations during a flood), which may be missed with classical and low frequency grab 59 sampling.

60

61 Keywords: GC-MS, phenylureas, triazines, passive sampler, water monitoring. 


\section{Introduction}

The European framework directive in the field of water policy $2000 / 60 /$ EC seeks to

65 prevent deterioration, to enhance and to restore bodies of surface water, to achieve good chemical

66 and ecological status of such water and to reduce pollution from discharges and emissions of

67 hazardous substances. The evaluation of surface water chemical status requires reliable

68 concentration estimates of various organic pollutants such as herbicides. For this purpose, two

69 approaches can be considered: active sampling (grab or automated) or passive sampling. Grab

70 and low frequency sampling (every week or month) is the easiest and most common method,

71 however, it seldom accurately tracks concentration fluctuations of targeted compounds in natural

72 aqueous environments. Time-weighted average (TWA) concentrations can be estimated by the

73 collection of several repetitive grab samples with automatic samplers. However, the use of such

74 equipment is often physically and logistically difficult, and it generates a large number of

75 samples with a corresponding increase in analytical cost. For monitoring polar herbicides in

76 freshwater, the use of polar organic chemical integrative samplers (POCIS) allows estimates of

77 TWA concentrations (Alvarez et al., 2004; Alvarez et al., 2005). Nevertheless, the accuracy and

78 the precision of these passive samplers for determining the ambient concentrations in rivers have

79 not been fully demonstrated.

80 This work assessed POCIS reliability for sampling selected polar herbicides

81 (deethylterbuthylazine, terbuthylazine and isoproturon) in natural aqueous environments. We

82 spiked triplicates of POCIS with the chemicals of interest and determined their elimination into

83 river water after 9 days. Afterwards, the POCIS were immersed within two microcosms filled

84 with the same river water but fortified at different concentration level; a relatively constant 
85 concentration and pulsed concentration event scenarios were considered. In fact, transient, high

86 environmental concentration events were simulated in one microcosm in order to determine the

87 capacity of the POCIS for integrating short-term large concentration increases. We also studied

88 the effects of turbulence and the eventual biofouling on both the precision and accuracy of TWA

89 concentrations estimated with the POCIS.

90 


\section{Experimental}

\subsection{Chemicals and materials}

Acetonitrile supragradient, methanol gradient and water gradient (HPLC grade) were 96 purchased from ICS-Science Groupe (Gradignan, France), ethyl acetate (HPLC grade) was

97 provided by Riedel-de Haën (Saint-Quentin-Fallavier, France). $1 \mathrm{~mL}$ empty polypropylene solid98 phase extraction (SPE) tubes with polyethylene (PE) frits (20 $\mu \mathrm{m}$ porosity) and Oasis HLB bulk 99 sorbent $(60 \mu \mathrm{m})$ were purchased from Supelco (Saint-Quentin-Fallavier, France) and Waters 100 (Guyancourt, France), respectively. Hydrophilic polyethersulfone (PES) SUPOR 100 Membrane

101 Disc Filters $(0.1 \mu \mathrm{m}, 90 \mathrm{~mm}$ membrane diameter) were purchased from Pall (Saint-Germain-en102 Laye, France). Oasis HLB cartridges (6 mL, $500 \mathrm{mg}, 60 \mu \mathrm{m})$ were provided by Waters (France). 103 Pharmaceutical POCIS were provided by Exposmeter (Tavelsjö, Sweden). All analytical 104 standards (purity $\geq 98 \%$ ) were purchased from Dr. Ehrenstorfer (Augsburg, Germany): 105 deethylterbuthylazine (DET), terbuthylazine, isoproturon and atrazine d5.

\subsection{Solid-phase extraction of water}

Preconcentration of the analytes from water samples was accomplished by using SPE 110 with Oasis HLB cartridges. Prior to SPE, 200-mL water samples (pH adjusted to 7) were filtered 111 using GF/F glass microfibre filters $(0.7 \mu \mathrm{m}$ pore size). Afterwards, $10 \mu \mathrm{L}$ of a stock solution 112 (acetonitrile) containing $100 \mathrm{ng} \mu \mathrm{L}^{-1}$ of atrazine $\mathrm{d} 5$ (surrogate), was added to the water samples,

113 resulting in fortification level of $5 \mu \mathrm{g} \mathrm{L} \mathrm{L}^{-1}$. SPE was conducted using a VisiPrep 12-port manifold 
114 (Supelco, France). The conditioning, extraction and rinsing steps were carried out under a 53.33

$115 \mathrm{kPa}$ vacuum. The SPE cartridges were successively washed with $10 \mathrm{~mL}$ of methanol, conditioned 116 with $10 \mathrm{~mL}$ of HPLC grade water, loaded with $200-\mathrm{mL}$ water samples, then rinsed with $20 \mathrm{~mL}$ of

117 HPLC grade water and dried with a stream of nitrogen for 30 minutes. Elutions were achieved 118 with $5 \mathrm{~mL}$ of methanol. The $5-\mathrm{mL}$ extracts were blown under a gentle stream of nitrogen and

119 dissolved within $1 \mathrm{~mL}$ of ethyl acetate prior to the GC-MS analyses. The final concentration of

120 the surrogate was about $1 \mathrm{mg} \mathrm{L}^{-1}$ after SPE extractions. The recoveries (Table 1) were optimized

121 with the extraction of $200 \mathrm{~mL}$ of both tap and river waters fortified with $5 \mu \mathrm{g} \mathrm{L}^{-1}$ of DET, 122 terbuthylazine, isoproturon and atrazine $\mathrm{d} 5(\mathrm{n}=10)$.

\section{2.3. Recoveries from POCIS} enclosed between two polyethersulfone (PES) membranes. The membrane-sorbent-membrane

128 layers are compressed between two holder washers $(5.1 \mathrm{~cm} \mathrm{I.D.,} 8.9 \mathrm{~cm}$ O.D.). The total 129 exchanging surface area of the membrane (both sides) is approximately $41 \mathrm{~cm}^{2}$ and the surface 130 area per mass of sorbent ratio is approximately $200 \mathrm{~cm}^{2} \mathrm{~g}^{-1}$. After the exposure in water, each 131 POCIS was opened and the sequestration medium (i.e. Oasis HLB) was transferred in a $50 \mathrm{~mL}$ 132 glass beaker with $2 \times 20 \mathrm{~mL}$ washes of HPLC grade water. The sorbent was transferred into a 1 $133 \mathrm{~mL}$ empty SPE tube with a PE frit and packed under vacuum by using a Visiprep SPE Manifold. 134 Afterwards, another polyethylene frit was added to the top of the SPE cartridge. All the cartridges 135 were washed with $20 \mathrm{~mL}$ of HPLC grade water and dried with a stream of nitrogen for 30 136 minutes. Elutions were achieved with $5 \mathrm{~mL}$ of methanol. $10 \mu \mathrm{L}$ of a stock solution (acetonitrile) 137 containing $100 \mathrm{ng} \mu \mathrm{L}^{-1}$ of atrazine D5 was added before the evaporation of the methanol with a 
138 gentle stream of nitrogen. The final extract was dissolved within $1 \mathrm{~mL}$ of ethyl acetate prior to

139 the GC-MS analyses.

140 Table 1. Analytical parameters and sampling rates of DET, terbuthylazine and isoproturon.

141

\begin{tabular}{cccc}
\hline Herbicides & DET & Terbuthylazine & Isoproturon \\
\hline Classes & $\begin{array}{c}\text { Triazine } \\
\text { metabolite }\end{array}$ & Triazine & Phenylurea \\
Retention times (min) & 21.85 & 24.05 & $12.90^{\mathrm{a}}$ \\
Fragments (m/z) & $145,186^{\mathrm{b}}, 201$ & $173,214^{\mathrm{b}}, 229$ & $146^{\mathrm{b}}, 161$ \\
$\mathrm{SPE}$ recoveries $(\%)^{\mathrm{c}}$ & $95(3)$ & $100(7)$ & $106(5)$ \\
$\operatorname{log~K}_{\mathrm{ow}}{ }^{\mathrm{d}}$ & 1.98 & 3.21 & 2.87 \\
$\mathrm{k}_{\mathrm{u}}\left(\mathrm{mL} \mathrm{g}^{-1} \mathrm{~d}^{-1}\right)^{\mathrm{e}}$ & $1025(28)$ & $1253(48)$ & $1088(51)$ \\
$\mathrm{R}_{\mathrm{s}}\left(\mathrm{mL} \mathrm{d}^{-1}\right)^{\mathrm{e}}$ & $205(6)$ & $251(10)$ & $218(10)$ \\
\hline
\end{tabular}

142

a Isoproturon
${ }^{\mathrm{b}}$ Base peak.

${ }^{\mathrm{c}}$ Fortification of tap and river waters ( \pm 1 S.D, $\mathrm{n}=10$ ).

${ }^{\mathrm{d}} \log \mathrm{K}_{\mathrm{ow}}$ for $\mathrm{pH}=7-8$ (Barceló \& Hennion, 1997; Hansch \& Leo, 1987)

${ }^{\mathrm{e}}$ Data ( \pm 1 S.D) from (Mazzella et al., 2007)

\subsection{GC-MS determination of herbicides}

155 chromatograph was coupled to a GCQ/POLARIS ion trap mass spectrometer (Thermo Electron

156 Corporation, MA, USA). The transfer line was held at $280{ }^{\circ} \mathrm{C}$ and the source at $240{ }^{\circ} \mathrm{C}$. Electron

157 impact mass spectra were acquired at $70 \mathrm{eV}$. Quantitative analysis were acquired in full scan 
158 mode from 100 to $350 \mathrm{amu}$. The total scan time was set to $0.68 \mathrm{~s}$ (6 microscans) and the max ion

159 time was kept constant at $25 \mathrm{~ms}$. Retention times, and quantitative and characteristic fragments of

160 DET, terbuthylazine and isoproturon are given in Table 1. Atrazine d5 was used as internal

161 standard (retention time: $23.30 \mathrm{~min}, \mathrm{~m} / \mathrm{z}=205$ ). A volume of $2 \mu \mathrm{L}$ (samples dissolved within

162 ethyl acetate) was injected on a splitless injector $\left(270{ }^{\circ} \mathrm{C}, 138 \mathrm{kPa}\right.$ pressure pulse for $\left.1.2 \mathrm{~min}\right)$.

163 Helium was used as carrier gas at a constant flow rate of $1 \mathrm{~mL} \mathrm{~min}^{-1}$. The temperature program

164 was $40{ }^{\circ} \mathrm{C}$ for $1.2 \mathrm{~min}$, then $15^{\circ} \mathrm{C} \mathrm{min}-1$ up to $160{ }^{\circ} \mathrm{C}$ and $4{ }^{\circ} \mathrm{C} \min ^{-1}$ to $270{ }^{\circ} \mathrm{C}$ followed by a 3.3

165 min isotherm (total running time: $40 \mathrm{~min}$ ).

\section{2.5. Dissolved organic carbon measurements}

169 The water samples were filtered using GF/F glass microfibre filters $(0.7 \mu \mathrm{m}$ pore size $)$ and

170 the concentrations of dissolved organic carbon (DOC) were measured using a model 1010 OI

171 Analytical carbon analyzer with a 1051 auto-sampler (Bioritech, France). The total organic

172 carbon analyses were performed with an high-temperature persulfate oxidation technology and

173 according the European standard ISO 8245:1999 (1999).

175 2.6. Microcosm experimental design and POCIS exposure

As shown in Figure 3, the POCIS ( $n=3)$ were immersed into two different glass 178 microcosms $\mathrm{A}$ and $\mathrm{B}$ each filled with $50 \mathrm{~L}$ of river water from Anan (southwest part of France).

179 The river water was characterized by a $\mathrm{pH} 7.67$ and a low dissolved organic carbon content $180\left(\mathrm{DOC}=1.69 \pm 0.03 \mathrm{mg} \mathrm{L}^{-1}\right)$. Prior to use, concentrations of isoproturon, DET and terbuthylazine 
181 were determined in the river water. Background concentrations of the chemicals of interest were 182 lower than the LODs $\left(0.05-0.15 \mu \mathrm{g} \mathrm{L}{ }^{-1}\right)$. The microcosms A and B were initially spiked with 183 approximately $5 \mu \mathrm{g} \mathrm{L}^{-1}$ and $25 \mu \mathrm{g} \mathrm{L} \mathrm{L}^{-1}$ of test compounds, respectively. Another microcosm with 184 unfortified river water was used as a blank control for the POCIS. During the exposure, 185 concentrations were relatively constant in microcosm A (i.e. standard addition was not required 186 after the initial spiking), whereas the river water was fully changed in microcosm B after 3 days. 187 Turbulent conditions were obtained by using submersible pumps. Flow velocities in the 188 microcosms varied from 15 to $50 \mathrm{~cm} \mathrm{~s}^{-1}$. The temperature was kept constant $\left(21 \pm 1^{\circ} \mathrm{C}\right)$ and the 189 experiment was carried out with natural light. SPE were performed at time zero $\left(\mathrm{t}_{0}\right)$ and every 3 190 days ( $\mathrm{t}_{0}, 3-\mathrm{d}, 6-\mathrm{d}$ and $\left.9-\mathrm{d}\right)$, resulting in 4 grab samples per microcosm. Both concentration and 191 standard deviation values were recovery corrected. The time weighted average concentrations 192 (Figure 2) were expressed for 3-day intervals and then for the whole exposure period (9 days).

193 All the triplicates of POCIS were sampled after 9 days of exposure.

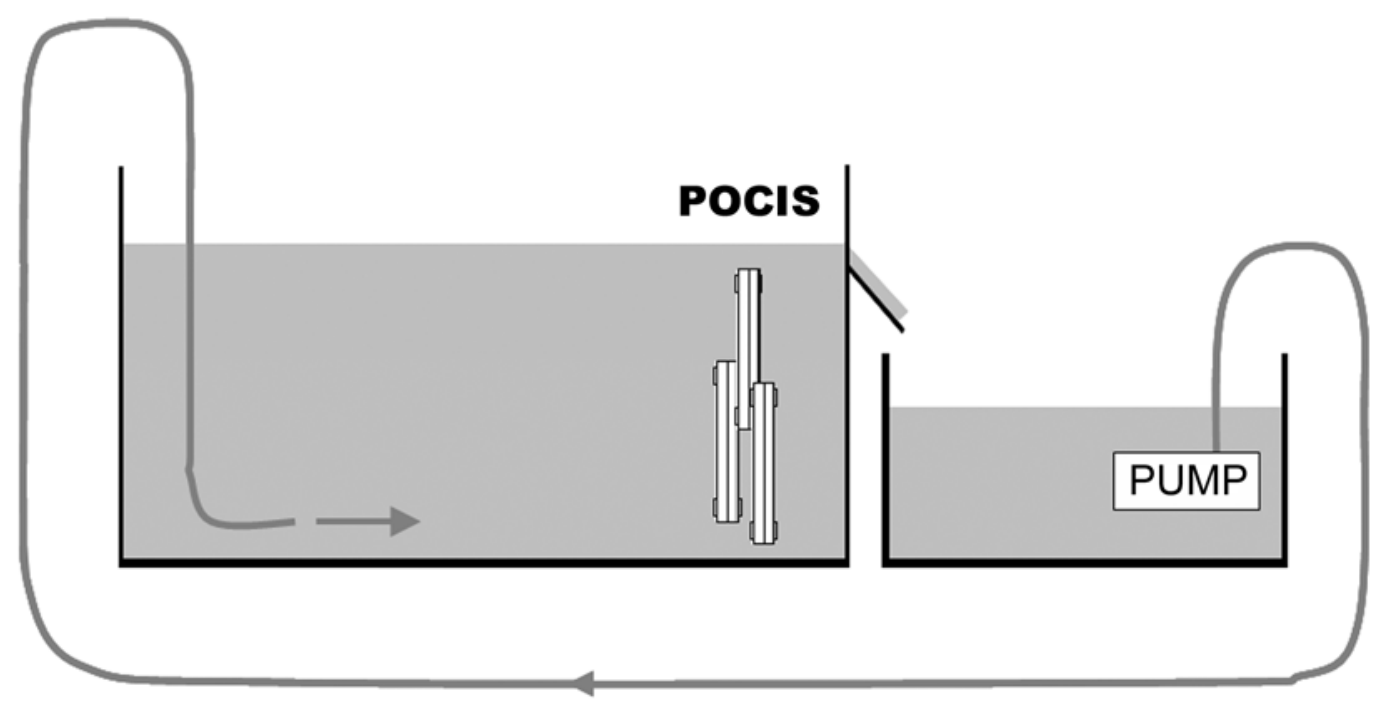


197 Figure 1. Experimental design of microcosms A and B. Triplicate POCIS were immersed into

198 river water for 9 days and exposed to flow velocities ranging from 15 to $50 \mathrm{~cm} \mathrm{~s}^{-1}$.

2.7. Spiking of POCIS sorbent with DET, terbuthylazine and isoproturon

A solution of $1 \mathrm{mg} \mathrm{L}^{-1}$ of DET, terbuthylazine and isoproturon was prepared in methanol. $50 \mathrm{~mL}$ of this solution was added to $5 \mathrm{~g}$ of Oasis HLB bulk sorbent and sonicated for $5 \mathrm{~min}$. The

204 solvent was eliminated with a rotary evaporator and the sorbent was dried at $60{ }^{\circ} \mathrm{C}$ for $1 \mathrm{~h}$. We

205 obtained $5 \mathrm{~g}$ of Oasis HLB bulk sorbent spiked with $10 \mu \mathrm{g} \mathrm{g}^{-1}$ of each of the test chemicals.

206 Three reference cartridges were prepared by transferring $200 \mathrm{mg}$ of the fortified sorbent into 1

207 mL empty polypropylene SPE tubes with PE frits. The elution (5 mL of methanol) and the GC-

208 MS analysis of the reference cartridges revealed initial concentrations $\left(\mathrm{C}_{0}\right)$ of $8.3 \mu \mathrm{g} \mathrm{g}^{-1}(7.8 \%$

$209 \mathrm{RSD}), 7.4 \mu \mathrm{g} \mathrm{g}^{-1}$ (4.1\% RSD) and $7.7 \mu \mathrm{g} \mathrm{g}^{-1}$ (4.4\% RSD) for DET, terbuthylazine and

210 isoproturon, respectively. Three POCIS were prepared with $200 \mathrm{mg}$ of the same fortified sorbent.

211 The POCIS were exposed in a microcosm filled with $50 \mathrm{~L}$ of river water. The flow and

212 temperature conditions were as described above. The 3 POCIS were sampled after 9 days of

213 exposure. The sorbents were transferred into $1 \mathrm{~mL}$ empty SPE tubes with PE frits, eluted with 5

$214 \mathrm{~mL}$ of methanol and dried under a gentle stream of nitrogen $(1 \mu \mathrm{g}$ of atrazine D5 was added as

215 internal standard before the solvent elimination). The extracts were dissolved within $1 \mathrm{~mL}$ of

216 ethyl acetate prior to the GC-MS analysis. 

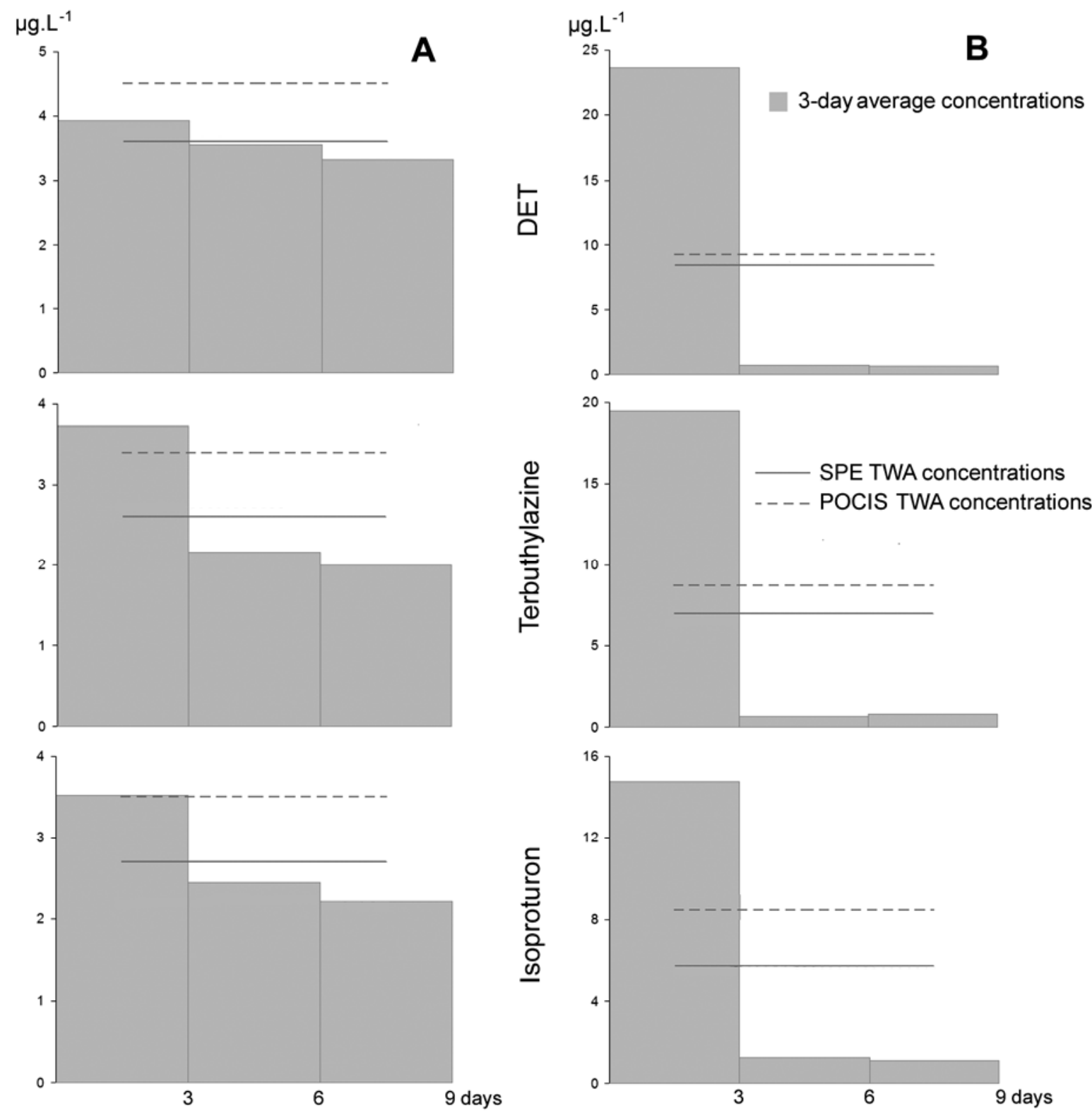

218 Figure 2. Time-weighted average concentrations of DET, terbuthylazine and isoproturon 219 (microcosms A and B) calculated from repetitive grab sampling and from POCIS. 


\section{Theory and modelling}

Assuming isotropic exchange, ambient concentrations of the contaminants can be

225 Huckins et al., 1999; Stuer-Lauridsen, 2005; Vrana et al., 2005):

$$
\mathrm{C}_{\text {POCIS }}=C_{w} K_{s w}\left(1-e^{-k_{e} t}\right)
$$

227 Where $\mathrm{C}_{\text {POCIS }}$ is the concentration $\left(\mu \mathrm{g} \mathrm{g}^{-1}\right)$ of the analyte in the sorbent, $\mathrm{C}_{\mathrm{w}}$ the TWA 228 concentration $\left(\mu \mathrm{g} \mathrm{L}^{-1}\right)$ of the analyte in water, $\mathrm{K}_{\mathrm{sw}}$ the POCIS-water partition constant $\left(\mathrm{L} \mathrm{g}^{-1}\right)$ and

$229 \mathrm{k}_{\mathrm{e}}$ the elimination rate constant $\left(\mathrm{d}^{-1}\right)$. Details of the model development and the conditions have 230 been presented and discussed for the semipermeable membrane devices (SPMDs) (Huckins et al., 231 1993; Huckins et al., 1999) and applied to the POCIS (Alvarez, 1999; Alvarez et al., 2004;

232 Mazzella et al., 2007). If the elimination rate $\mathrm{k}_{\mathrm{e}}$ is negligible compared to the uptake rate $\mathrm{k}_{\mathrm{u}}\left(\mathrm{L} \mathrm{g}^{-1}\right.$

$233 \mathrm{~d}^{-1}$ or $\mathrm{mL} \mathrm{g}^{-1} \mathrm{~d}^{-1}$ ), then the POCIS acts as an infinite sink for the chemical of interest and analyte 234 uptake is linear for several weeks $\left(\mathrm{t} \leq(\ln 2) / \mathrm{k}_{\mathrm{e}}\right)($ Alvarez et al., 2004). In this case, Eq. 1 can be 235 reduced to:

$236 C_{\text {POCIS }}=C_{w} k_{u} t$

237 If we introduce the mass of the sorbent $\mathrm{M}_{\text {POCIS }}(\mathrm{g})$, we can rearrange Eq. 2 to an equivalent 238 relationship with the sampling rate $\mathrm{R}_{\mathrm{s}}\left(\mathrm{mL} \mathrm{d}^{-1}\right)$, instead of the uptake rate constant $\mathrm{k}_{\mathrm{u}}$ :

$$
\mathrm{C}_{\text {POCIS }}=\frac{C_{w} R_{s} t}{M_{\text {POCIS }}}
$$

240 Eq. 3 and $\mathrm{R}_{\mathrm{s}}$ values derived from a previous calibration experiment (Mazzella et al., 2007; Table

4) were used for TWA concentration estimates with the POCIS. 


\section{Results and discussion}

\subsection{Desorption of DET, terbuthylazine and isoproturon from POCIS}

We studied the desorption of DET, terbuthylazine and isoproturon. As reported in Table

2475 , elimination was negligible $(3 \%)$ for DET and relatively low for both terbuthylazine and 248 isoproturon (11-12\%) after 9 days. These results are in good agreement with previous works 249 indicating a strong retention for some polar herbicides such as atrazine, diazinon, diuron, 250 isoproturon (Alvarez et al., 2004) and simazine (Mazzella et al., 2007). However, the POCIS are 251 frequently deployed for several weeks in the field (Alvarez et al., 2004; Alvarez et al., 2005;

252 Macleod et al., 2007; Matthiessen et al., 2006) and for long exposure times, the desorption 253 phenomena are probably not negligible. In this case we have to investigate the elimination rates 254 in further detail.

255 Table 2. Desorption of the chemical of interest.

256

\begin{tabular}{ccc}
\hline Herbicides & $\mathrm{C}_{9-\mathrm{d}} \mathrm{d} \mathrm{C}_{0}{ }^{\mathrm{a}}$ & $\% \mathrm{RSD}$ \\
\hline DET & 0.97 & 1.4 \\
Terbuthylazine & 0.88 & 12.5 \\
Isoproturon & 0.89 & 18.0 \\
\hline
\end{tabular}

${ }^{\text {a }}$ Ratio between the concentrations after 9 days and the initial concentrations.

259 Table 3. Parametric Z-test (critical Z value of 1.960 and $95 \%$ confidence interval) for comparing 260 the time-weighted average (TWA) concentrations calculated from repetitive grab sampling and 261 from the POCIS in the microcosms A and B. 


\begin{tabular}{|c|c|c|c|c|c|c|}
\hline Herbicides & DET & Terbuthylazine & Isoproturon & DET & Terbuthylazine & Isoproturon \\
\hline Microcosms & & A & & & B & \\
\hline Differences $(\mu \mathrm{g} \mathrm{L})^{\mathrm{a}}$ & 0.90 & 0.77 & 0.77 & 0.90 & 1.77 & 2.80 \\
\hline Overestimation (\%) & +25 & +29.5 & +28.5 & +11 & +25 & +49 \\
\hline $\mathrm{Z}^{\mathrm{b}}$ (Observed value) & 3.402 & 2.203 & 1.000 & 1.372 & 1.919 & 2.750 \\
\hline $\begin{array}{l}\text { p-values }{ }^{\mathrm{b}} \\
\text { (Two-tailed) }\end{array}$ & 0.001 & 0.028 & 0.317 & 0.170 & 0.055 & 0.006 \\
\hline
\end{tabular}

263

264

265

266

267

268

269

270

271

272

273

274

275

276

277

278

279

280

281

282

${ }^{a}$ Differences between the means of the TWA concentrations calculated from POCIS and from grab samples.

${ }^{\mathrm{b}}$ Z-tests and p-values were calculated with XLSTAT-PRO (Addinsoft).

\subsection{Comparison between solid-phase extraction and POCIS with various conditions}

In order to facilitate the comparison between the two approaches, the same sorbent (i.e.

Oasis HLB) was used for grab and passive sampling. In regard to the microcosm A, the concentration of DET was relatively constant while a steep decrease of both terbuthylazine and isoproturon concentrations was observed between 3 and 6 days (Figure 4). This decrease may be due to the adsorption of isoproturon and terbuthylazine on suspended particulate matter since these chemicals are characterized by a higher hydrophobicity $\left(\log \mathrm{K}_{\mathrm{ow}}=2.87\right.$ and 3.21, respectively) than DET $\left(\log \mathrm{K}_{\mathrm{ow}}=1.98\right)$. Concerning the microcosm $\mathrm{B}$, we simulated a peak exposure scenario by replacing the initial spiked medium by clear river water after 3 days (Figure 4).

The TWA concentrations (Figure 4) were determined with both SPE of grab samples and the POCIS exposed during 9 days. The results of a parametric test are reported in Table 6 (z-test, $\mathrm{p}=0.05$ ). For DET and terbuthylazine (microcosm A), the TWA concentrations calculated with the SPE $(n=10)$ and estimated with the POCIS $(n=3)$ were significantly different. In regard to the microcosm B, the reference concentrations (SPE) and the estimated concentrations (POCIS) are 
283 significantly different for isoproturon only. In the other cases (isoproturon in microcosm A and

284 both DET and terbuthylazine in microcosm B), there were no significant differences between the 285 two sampling methods. This may be due to both a slight overestimation (especially for DET in 286 the microcosm B with $+11 \%$ ) and a high standard deviation. Globally, the concentrations were systematically and significantly overestimated with the POCIS (from +11 to $+49 \%$; Table 6 ) in comparison with the SPE procedure. This result is most likely due to the application of inadequate $\mathrm{R}_{\mathrm{s}}$ values previously determined during the calibration (Mazzella et al., 2007). observed a growth of algae on the glass wall of the microcosms whereas the biofilm formation was barely visible on the membranes of the POCIS. Consequently, we assumed that the PES membranes were probably not affected by the biofouling (Vrana et al., 2005) and the concentration overestimation should be attributed to the higher flow velocities for this experiment (from 15 to $50 \mathrm{~cm} \mathrm{~s}^{-1}$ ) than for the calibration $\left(2-3 \mathrm{~cm} \mathrm{~s}^{-1}\right.$ ) (Mazzella et al., 2007).

As suggested by some authors (Alvarez et al., 2004), the solute mass transfer is mainly controlled by the aqueous boundary layer. In other words, the sampling rates depend on the flow velocities and the turbulence. Some works (Gunold et al., In Press) showed for Empore SDB-XC disks that the influence of flow velocity on the sampling rates seems to play a minor role for

300 hydrophilic substances such as herbicides. However, the authors performed calibrations only at 301 relatively high flow velocities $\left(13.5 \mathrm{~cm} \mathrm{~s}^{-1}\right.$ and $\left.40 \mathrm{~cm} \mathrm{~s}^{-1}\right)$ and they did not use diffusion-limiting 302 membranes. The comparison with the POCIS is tenuous but such data indicates an increase of the 303 sampling rates with flow velocity until a certain threshold only. For polar chemicals sampled 304 with Empore SDB-RPS disks, Vermeiressen et al. (Vermeirssen et al., 2008) observed an 305 increase of accumulated amounts with increasing flow velocities (from 2.6 to $37 \mathrm{~cm} \mathrm{~s}^{-1}$ ). Their 306 results showed also curvilinear uptakes and earlier equilibriums for polar chemicals at flow 
307 velocities higher than $10 \mathrm{~cm} \mathrm{~s}^{-1}$, indicating a rapid increase of $\mathrm{k}_{\mathrm{e}}$ with flow velocity. However, a

308 direct comparison is still difficult since no diffusion-limiting membrane was used in this work as

309 well. If bulk flow rates in test microcosms are good predictors of chemical uptake rates in

310 boundary layer controlled passive samplers, then the relative differences in TWA concentrations

311 obtained from SPE and POCIS approaches should be relatively constant as shown in Figure 4 and

312 Table 6 for microcosm A. Regarding to microcosm B, the results were more variable with

313 overestimates ranging from $+11 \%$ to $+49 \%$. We observed during the POCIS calibration a slight

314 and variable increase in sampling rates occurring in the first five days (Mazzella et al., 2007).

315 Such a phenomenon is generally reduced with the POCIS presoaking (Alvarez, 1999) but it can

316 explain the variation of the sampling rates during the 3 day pulse experiment only. In this case,

317 short-term pollution peaks may be imprecisely integrated by the POCIS if such a phenomenon

318 occurs at the beginning of the exposure. Lastly, the concordance between the reference SPE

319 measurements and the POCIS concentration estimates could obviously be improved with the

320 application of microcosm-calibrated $R_{s}$. We can also use an appropriate performance reference

321 compounds (PRCs). The PRC approach was successfully developed and applied for the SPMDs

322 (Booij et al., 2002; Huckins et al., 2002) and in a previous work (Mazzella et al., 2007) we

323 suggested the use of the deisopropylatrazine as PRC since we observed isotropic exchanges and a

324 strong release of this chemical from the POCIS sorbent after only 10 days. The application of

325 such a PRC will be further investigated with in situ experiments.

In general, there is a paucity of studies on the uptake of short-term fluctuations with

328 passive samplers (Greenwood et al., 2007), especially for polar compounds. For the microcosm B

329 (Figure 4), unlike SPE of grab samples, passive samplers do not instantaneously reflect changes

330 in the environmental concentrations of chemicals, as response time must be considered. However, 
331 the results showed that the peaks of DET, terbuthylazine and isoproturon concentrations were 332 integrated by the POCIS. The largest differences in values derived from the two approaches 333 should be observed for comparisons where the time resolution for grab samples is low (i.e., 334 several days or some weeks between samples) and the concentrations measured change relatively 335 fast such as observed for microcosm B. Such conditions are frequently observed with small 336 drainage basin $\left(\leq 1000 \mathrm{~km}^{2}\right)$ and in this case the POCIS may be a really useful tool for detecting 337 episodic and short-term events (e.g. herbicide concentration increase during a rise in the water 338 level) which may be missed with classical and low frequency grab sampling. 


\section{5. Conclusion}

342 The POCIS method likely works well when appropriate sampling rates for analytes are

343 available. Unfortunately, the PRC approach for in situ calibration is not fully developed for

344 POCIS, which necessitated the use of sampling rates for test compounds measured at lower flow

345 velocities than the present study. Use of these inappropriate sampling rates for calculating water

346 concentrations of analytes from POCIS concentrations resulted in an expected systematic and

347 significant overestimation of water concentrations relative to SPE grab samples. Although,

348 POCIS derived water concentrations estimates were significantly overestimated relative to SPE

349 grab samples, the bias in the concentration values was not large as they ranged from 11 to $49 \%$

350 greater. Further studies with various real-world conditions (i.e. quiescent or highly turbulent

351 environments, variable temperature, occurrence of organic matter and biofouling, etc.) are

352 compulsory for determining the reliability of the POCIS for a quantitative approach.

\section{Acknowledgements}

356 The authors would like to thank B. Mechin, B. Delest, M. Bonnet and M. Boudigues for 357 their skilful technical assistance. 


\section{Tables}

361

362 Table 4. Analytical parameters and sampling rates of DET, terbuthylazine and isoproturon.

363

364 Table 5. Desorption of the chemical of interest.

365

366 Table 6. Parametric Z-test (critical $\mathrm{Z}$ value of 1.960 and $95 \%$ confidence interval) for comparing

367 the time-weighted average (TWA) concentrations calculated from repetitive grab sampling and

368 from the POCIS in the microcosms A and B. 


\section{Figures}

375 Figure 3. Experimental design of microcosms A and B. Triplicate POCIS were immersed into 376 river water for 9 days and exposed to flow velocities ranging from 15 to $50 \mathrm{~cm} \mathrm{~s}^{-1}$.

378 Figure 4. Time-weighted average concentrations of DET, terbuthylazine and isoproturon 379 (microcosms A and B) calculated from repetitive grab sampling and from POCIS. 


\section{References}

383

384

385

386

387

388

389

390

391

392

393

394

395

396

397

398

399

400

401

402

403

404

405

406

407

408

409

410

411

412

413

414

415

416

417

418

419

420

421

422

423

424

425

426

427

Directive 2000/60/EC of the European Parliament and of the Council of 23 October 2000 establishing a framework for Community action in the field of water policy. OJ L 327, 22.12.2000, 1-73.

1999. ISO 8245:1999 - Water quality - Guidelines for the determination of total organic carbon (TOC) and dissolved organic carbon (DOC).

Alvarez, D.A., (1999) Development of an integrative sampling device for hyrophilic organic contaminants in aquatic environments, $P h D, p p .160$. University of Missouri-Columbia.

Alvarez, D.A., Petty, J.D., Huckins, J.N., Jones-Lepp, T.L., Getting, D.T., Goddard, J.P., Manahan, S.E., 2004. Development of a passive, in situ, integrative sampler for hydrophilic organic contaminants in aquatic environments. Environ. Toxicol. Chem. 23, 1640-1648.

Alvarez, D.A., Stackelberg, P.E., Petty, J.D., Huckins, J.N., Furlong, E.T., Zaugg, S.D., Meyer, M.T., 2005. Comparison of a novel passive sampler to standard water-column sampling for organic contaminants associated with wastewater effluents entering a New Jersey stream. Chemosphere 61, 610-622.

Barceló, D., Hennion, M.-C., 1997. Trace determination of pesticides and their degradation products in water. Elsevier, Amsterdam.

Booij, K., Smedes, F., van Weerlee, E.M., 2002. Spiking of performance reference compounds in low density polyethylene and silicone passive water samplers. Chemosphere 46, 11571161.

Carabias-Martínez, R., García-Hermida, C., Rodríguez-Gonzalo, E., Soriano-Bravo, F.E., Hernández-Méndez, J., 2003. Determination of herbicides, including thermally labile phenylureas, by solid-phase microextraction and gas chromatography-mass spectrometry. J. Chromatogr. A 1002, 1-12.

Greenwood, R., Mills, G.A., Vrana, B., Allan, I., Aguilar-Martínez, R., Morrison, G., 2007. Chapter 9 Monitoring of priority pollutants in water using chemcatcher passive sampling devices. In: R. Greenwood, G.A. Mills, B. Vrana (Eds.), Comprehensive Analytical Chemistry Passive : Sampling Techniques in Environmental Monitoring, 48, Elsevier Science, Amsterdam. pp. 199-229.

Gunold, R., Schäfer, R.B., Paschke, A., Schüürmann, G., Liess, M., In Press. Calibration of the Chemcatcher passive sampler for monitoringselected polar and semi-polar pesticides in surface water. Environ. Pollut., 1-9.

Hansch, C., Leo, A., 1987. The Log P Database. Pomona College, Claremont, CA.

Huckins, J.N., Manuweera, G.K., Petty, J.D., Mackay, D., Lebo, J.A., 1993. Lipid-containing semipermeable membrane devices for monitoring organic contaminants in water. Environ. Sci. Technol. 27, 2489-2496.

Huckins, J.N., Petty, J.D., Lebo, J.A., Almeida, F.V., Booij, K., Alvarez, D.A., Cranor, W.L., Clark, R.C., Mogensen, B.B., 2002. Development of the Permeability/Performance Reference Compound Approach for In Situ Calibration of Semipermeable Membrane Devices. Environ. Sci. Technol. 36, 85-91.

Huckins, J.N., Petty, J.D., Orazio, C.E., Lebo, J.A., Clark, R.C., Gibson, V.L., Gala, W.R., Echols, K.R., 1999. Determination of Uptake Kinetics (Sampling Rates) by LipidContaining Semipermeable Membrane Devices (SPMDs) for Polycyclic Aromatic Hydrocarbons (PAHs) in Water. Environ. Sci. Technol. 33, 3918-3923. 
Macleod, S.L., McClure, E.L., Wong, C.S., 2007. Laboratory calibration and field deployment of the polar organic chemical integrative sampler for pharmaceuticals and personalcare products in wastewater and surface water. Environ. Toxicol. Chem. 26, 2517-2529. Contamination of headwater streams in the United Kingdom by oestrogenic hormones from livestock farms. Sci. Total Environ. 367, 616-630.

Mazzella, N., Dubernet, J.-F., Delmas, F., 2007. Determination of kinetic and equilibrium regimes in the operation of polar organic chemical integrative samplers: Application to the passive sampling of the polar herbicides in aquatic environments. J. Chromatogr. A $1154,42-51$.

Stuer-Lauridsen, F., 2005. Review of passive accumulation devices for monitoring organic micropollutants in the aquatic environment. Environ. Pollut. 136, 503-524.

Vermeirssen, E.L.M., Asmin, J., Escher, B.I., Kwon, J.-H., Steimen, I., Hollender, J., 2008. The role of hydrodynamics, matrix and sampling duration in passive sampling of polar compounds with Empore SDB-RPS disks. J. Environ. Monitor. 10 119-128.

Vrana, B., Allan, I.J., Greenwood, R., Mills, G.A., Dominiak, E., Svensson, K., Knutsson, J., Morrison, G., 2005. Passive sampling techniques for monitoring pollutants in water. TRAC-Trend Anal. Chem. 24, 845-868. 